\title{
A LEGITIMIDADE DO ABORTO NO PRIMEIRO TRIMESTRE GESTACIONAL SOB A ÉGIDE DA TEORIA TRANSCONSTITUCIONALISTA ${ }^{1}$
}

THE LEGITIMACY OF ABORTION IN THE FIRST GESTATIONAL QUARTER UNDER THE TRANSCONSTITUTIONALIST THEORY

Giulia de Paula LUPACHINI ${ }^{2}$

Fábio Cantizani Gomes ${ }^{3}$

ISSUE DOI: $10.21207 / 2675-0104.2018 .797$

\begin{abstract}
RESUMO
$\mathrm{O}$ tema proposto para pesquisa aborda a temática do aborto frente à teoria transconstitucionalista e, além disso, busca compreender os prejuízos relacionados à criminalização da prática no Brasil. A referência científica alicerça-se justamente na mudança de consciência da sociedade como um todo e, principalmente daqueles que compõem o sistema judiciário pátrio, tendo em vista que uma das formas de se instaurar um saudável debate de natureza transconstitucional, sobretudo no que diz respeito aos direitos humanos e fundamentais, ocorre a partir da instauração das pontes de conversação transversais por meio de Juízes e Tribunais, os quais são, segundo o autor Marcelo Neves, o centro de um sistema jurídico multicêntrico. Nesse sentido, a análise das últimas decisões do Supremo Tribunal Federal sobre
\end{abstract}

\footnotetext{
${ }^{1} \mathrm{O}$ presente artigo sintetiza a monografia de conclusão da pesquisa, realizada para o Programa Interno de Bolsas de Iniciação Científica (PIBIC 2017-2018) da Faculdade de Direito de Franca (FDF), Franca/SP.

${ }^{2}$ Discente da Faculdade de Direito de Franca (FDF), Franca/SP. Bolsista do Programa Interno de Bolsas de Iniciação Científica (PIBIC 2017-2018). Contato: lupachinig@gmail.com.

${ }^{3}$ Possui graduação em Direito pela Universidade Estadual Paulista Júlio de Mesquita Filho (1994) e mestrado em Direito pela Universidade Estadual Paulista Júlio de Mesquita Filho (2004). Doutorando pelo Centro Universitário de Bauru da Instituição Toledo de Ensino (2018). Atualmente é professor titular de Direito Constitucional da Faculdade de Direito de Franca e da Universidade de Franca. Tem experiência na área de Direito, com ênfase em Direito Constitucional.
} 
o assunto, norteiam a investigação sobre a tendência de resolução dos problemas que envolvem a questão do aborto, de forma justa e equilibrada, com fundamento na Teoria Transconstitucionalista.

Palavras-chave: Aborto; Transconstitucionais; Supremo Tribunal Federal.

\section{ABSTRACT}

The topic proposed for research addresses the issue of abortion in relation to the transconstitutionalist theory and, in addition, seeks to understand the damages related to the criminalization of the practice in Brazil. The scientific reference is based precisely on a change in the conscience of society as a whole, and especially of those who make up the country's judicial system, given that one of the ways to establish a healthy debate of a trans-constitutional nature, especially with regard to human rights and fundamental rights, comes from the establishment of transversal bridges through Judges and Courts, which are, according to the author Marcelo Neves, the center of a multicentric legal system. In this sense, the analysis of the last decisions of the Federal Supreme Court on the subject, guide the investigation on the tendency to solve the problems that involve the abortion question, in a fair and balanced way, based on the Transconstitutionalist Theory.

Keywords: Abortion; Transconstitutional; Federal Court of Justice.

\section{INTRODUÇÃO}

As barreiras físicas e ideológicas, antes relacionadas à ideia de soberania de cada Estado-país, foram superadas em consonância com os problemas relacionados aos direitos humanos ou direitos fundamentais, de tal maneira que sua discussão se faz relevante aos ordenamentos jurídicos de forma global, deixando de ser um privilégio constitucional do Estado (esses fenômenos de ampliação do alcance da norma jurídica e possibilidade de aprendizado entre as cortes são reconhecidos como transconstitucionalismo). Nesse sentido, escreve Marcelo Neves:

Contra essas tendências, o transconstitucionalismo implica o reconhecimento de que as diversas ordens jurídicas entrelaçadas na solução de um problema - caso constitucional - a saber, de direitos fundamentais ou humanos e de organização legítima do poder -, que lhes seja concomitantemente relevante, devem buscar formas transversais de articulação para a solução do problema, cada uma delas observando a outra, para compreender seus próprios limites e possibilidades de contribuir para solucioná-1o ${ }^{4}$.

Adiante, prossegue referido autor afirmando que "o transconstitucionalismo implica o reconhecimento dos limites de observação de uma determinada ordem, que admite alternativa: o ponto cego, o outro pode ver5".

\footnotetext{
${ }^{4}$ NEVES, Marcelo. Transconstitucionalismo. São Paulo: WMF Martins Fontes, 2009, p. 297.

${ }^{5}$ NEVES, Marcelo. Transconstitucionalismo. São Paulo: WMF Martins Fontes, 2009, p. 298.
} 
A questão de pesquisa está no aprofundamento da temática transconstitucionalista, permitindo que se levante discussão a respeito da descriminalização do aborto no Brasil no primeiro trimestre gestacional, assunto que embora extremamente relevante, encontrase eivado de preconceitos de diversos grupos que historicamente ocupam cargos de influência econômica e política no país e procuram inibir o debate por seguirem suas convicções pessoais pautadas em fundamentalismos éticos, morais, religiosos e filosóficos, ao invés de apoiar o debate de forma racional, humano e imparcial.

A natureza do presente artigo relaciona-se com a qualidade exploratória do tema, pois analisa a necessidade de se discutir a questão do aborto, sob a aproximação de um entendimento transconstitucional, objetivando identificar ideias e pensamentos que corroborem com a essência didática da teoria. As pesquisas bibliográficas, em especial a obra sobre o transconstitucionalismo, bem como os estudos de casos, permitem a formação de um raciocínio voltado à integração dos assuntos e a busca de respostas sobre a eficiência ou não da criminalização do aborto no Brasil.

A conversação sobre $o$ assunto com outras cortes estrangeiras mostra-se necessária para garantir a proteção dos direitos humanos dentro dos territórios nacionais. Ademais, a experiência de uma nação ou região pode servir como inspiração e informação para outras nações e regiões do globo.

\section{INTRODUÇÃO AO TRANSCONSTITUCIONALISMO}

$\mathrm{O}$ constitucionalismo surge em meio às incertezas como propulsor para a solução das aflições enfrentadas por uma sociedade de complexidade sistêmica notável. Nisso fundado, se ergue o princípio do governo limitado e passa a ser definido um modelo de organização política do estado hábil a garantir os direitos fundamentais.

Trata- se a limitação ao poder interno e externo, a separação dos poderes, despersonalizando - os e o apelo aos direitos sociais contra qualquer resquício de arbítrio regimental, de uma resposta funcional e normativa aos problemas desencadeados pelo regime absolutista. Cada 
Estado foi criador de sua própria constituição do constitucionalismo, no momento apropriado para seu feito, de acordo com uma visão social, crença e fundamentos políticos, éticos e morais.

Nas palavras de Canotilho: "Constitucionalismo é a teoria (ou ideologia) que ergue o princípio do governo limitado indispensável à garantia dos direitos em dimensão estruturante da organização políticosocial de uma comunidade".

Neste sentido, o constitucionalismo moderno representará uma técnica específica de limitação do poder com fins garantísticos. Pois, nas palavras do referido autor, o conceito de constitucionalismo transporta, assim, um claro juízo de valor. É, no fundo, uma teoria normativa da política, tal como a teoria da democracia ou a teoria do liberalismo ${ }^{6}$.

$\mathrm{O}$ direito constitucional sofreu inúmeras transformações nas últimas décadas. No Brasil, vale citar, ocorreu a centralização da constituição federal em face do ordenamento jurídico como um todo, o que amenizou as discrepâncias entre direito público e privado, sem, entretanto, associá-los. A importância desse processo pode ser identificada por suas consequências imediatas, como, por exemplo, a concessão não apenas de supremacia formal, prevista na fase anterior da constitucionalização da constituição, mas também a nova dimensão de supremacia material.

Quando a constituição assume o papel central do ordenamento jurídico, torna-se uma célebre ferramenta jurisdicional, pois, como previsto por Schier $^{7}$, provoca a técnica de filtragem constitucional, ou, ainda, a chamada constitucionalização dos direitos. A partir disso, se iniciam as releituras indiretas ou diretas de todo sistema normativo ordinário sob a égide da influência e primazia da Carta Magna.

Doravante o fim do século XX e as reformas consequentes desse, ocorreu a constitucionalização democrática do direito constitucional. Nesse sentido, foram estabelecidos os pilares de sua sustentação, sendo esses: a eclosão do princípio do poder limitado; a indispensável presciência da dignidade da pessoa humana, enquanto princípio primordial para o nascimento dos demais direitos fundamentais; centralidade da constituição como instrumento de aplicabilidade direta de seus efeitos materiais, ausentando-se da dependência do texto legislado, e conferindo normatividade aos direitos e valores sociais formatados em princípios.

\footnotetext{
${ }^{6}$ CAnotilho, José Joaquim Gomes. Direito Constitucional e Teoria da Constituição. 7 ed. Coimbra/Portugal: Almedina. 2003.

7 Schier, Paulo Ricardo. Novos Desafios da Filtragem Constitucional no Momento do Neoconstitucionalismo. A\&C de Dir. Administrativo e Constitucional, Belo Horizonte, ano 5, n. 20, p. 1-255, abr./jun.2005.
} 
As necessidades políticas e jurídicas transformaram o raciocínio iluminista e formaram uma nova sociedade extremamente complexa e pluralista, a qual passou a despertar preocupação diversa das que até o presente momento foram citadas, ou seja, além do conteúdo constitucionalista clássico, o qual se preocupa com a limitação e separação de poderes, bem como a formulação de garantias fundamentais.

O homem que renasce sobre essa nova perspectiva política transforma os paradigmas do ordenamento jurídico a partir de uma racionalidade limitativa e organizacional. Aqui, o Direito Constitucional transfigura-se importante mecanismo para a regulação do direito, por prever limites, concessão de informações e redução da interferência descabida entre os sistemas sociais autônomos como um todo (político, econômico, social, cultural).

Nas palavras de Teubner, o que se pode observar é não mais a ação de um pensamento constitucional que almeja a emancipação social das amarras de um Estado desregulado e centralizador, mas enquadra-se perfeitamente no conceito de direito reflexivo, pós intervencionistas, característico da pós-modernidade:

A constituição é um estatuto reflexivo que, através de certos procedimentos, do apela a auto regulações, de sugestões no sentido da evolução político-social permite a existência de uma pluralidade de opções políticas, a compatibilização dos dissensos, a possibilidade de vários jogos políticos, a garantia da mudança através da construção de rupturas ${ }^{8}$ (TEUBNER, LADEUR).

O processo de globalização dos meios técnico-científicos, acrescidos da massificação e integração do contingente populacional resultou em enorme transformação das necessidades e expectativas do corpo social. Neves, leciona que esse direcionamento do constitucionalismo foi o responsável pelo surgimento da chamada "sociedade multicêntrica" ou "policontextural".

O constitucionalismo relaciona-se com transformações estruturais que engendraram as bases para o surgimento da sociedade moderna. $\mathrm{O}$ incremento da complexidade social levou ao impasse da formação social diferenciada hierarquicamente da prémodernidade, fazendo emergir a pretensão crescente de autonomia das esferas de comunicação, em termos de sistemas diferenciados funcionalmente na sociedade moderna. Há não só um desintrincamento de lei, poder e saber, nem apenas a obtenção da

${ }^{8}$ CANOTILHO, José Joaquim Gomes. Direito constitucional e teoria da constituição. Coimbra: Almedina, 1997. 
liberdade religiosa e econômica pelo homem, mas um amplo processo de diferenciação sistêmico-funcional ${ }^{9}$.

Cumpre ressaltar que, essa era pós-positivista em que se insere o Direito Constitucional, não surge como afronta às leis escritas, tampouco questiona a relevância jurídica do texto constitucional tradicional, mas reaproxima os fundamentos éticos e filosóficos à realidade jurídica no caso concreto.

\section{UM OLHAR CONSTITUCIONAL PARA ALÉM DAS FRONTEIRAS DO ESTADO COMO RESPOSTA À SOCIEDADE PLURALISTA E MULTICÊNTRICA DA PÓS-MODERNIDADE}

A globalização não se dedicou exclusivamente à sistematização e modernização dos meios científicos e tecnológicos, mas também acentuou os problemas relacionados aos direitos humanos de tal forma que as Constituições nacionais estatais, ainda que de extrema importância, não conseguiram, de forma isolada, solucioná-los. A complexidade e diversidade de uma sociedade com espírito revolucionário que emerge no fim do século XVIII, traz consigo novos desafios a serem mitigados.

À vista disso, se tornou inegável a necessidade de adequação do ordenamento jurídico às mudanças do corpo social, a fim de mantê-lo suficiente para solucionar, principalmente, os intensos conflitos em relação aos direitos fundamentais ou humanos.

As questões que envolvem matérias de Direito Constitucional, importância dos direitos fundamentais e limitação do poder interno e externo, perpassaram os limites territoriais, políticos e ideológicos, das ordens jurídicas mais díspares possíveis e se tornaram concomitantemente relevantes a essas.

Assim, o autor Marcelo Neves, formulador e propagador da teoria Transconstitucionalista no Brasil, acredita que a evolução da sociedade hodierna reflete não apenas no modo de comunicar-se, mas também de refletir sobre questões político-jurídicas, superando-se as ideias de um único e soberano estatismo constitucional que aprisionam a evolução do ordenamento como um todo.

\footnotetext{
${ }^{9}$ NEVES, Marcelo. Transconstitucionalismo. São Paulo: Martins Fontes, 2009, p. 23.
} 
Por outro lado, o estudioso afirma ainda, dizer que há semelhança de questões conflituosas entre diferentes ordens, não significa instintivamente a crença na necessidade de um cosmopolitismo constitucional. Pois a ideia de se criar uma Constituição global é inviável ou, no mínimo, utópica. Não seria possível atribuir aos países tão diferentes que compõem o globo um mesmo manto constitucional, tendo em vista as discrepâncias entre seus conceitos éticos, morais, políticos e, inclusive, religiosos.

O transconstitucionalismo implica o reconhecimento de que as diversas ordens jurídicas entrelaçadas na solução de um problema caso-constitucional - a saber, de direitos fundamentais ou humanos e de organização legítima do poder - , que lhes seja concomitantemente relevante, devem buscar formas transversais de articulação para a solução do problema, cada uma delas observando a outra, para compreender os seus próprios limites e possibilidades de contribuir para solucioná-los ${ }^{10}$.

A teoria transconstitucionalista emerge para o desafogar das ordens jurídicas sobre problemas característicos da integração social, cientifica e tecnológica entre os diversos campos do globo. A sociedade hodierna avançou não apenas em modernidade instrumental, mas também em demandas jurídicas, políticas e coletivas.

O constitucionalismo moderno restou inflacionado em diversas questões, as quais não podem ser resolvidas de pronto, pois exigem uma solução plausível, impossível de ser alcançada por estar presa num posicionamento estatal ideologicamente limitado.

A sociedade multicêntrica e pluralista do pós-modernismo preocupa-se com os direcionamentos de um direito meramente redacional, sem a capacidade operativa em face de uma enorme demanda sobre os institutos que afrontam a garantia e o livre exercício de direitos fundamentais.

Por este motivo, se tornou inegável a essencial integração e observação dos pilares científicos e políticos de forma mutua pelos diversos ordenamentos jurídicos, pois os problemas de cunho constitucional deixaram de se reconhecer a partir de limites territorialmente estabelecidos e tornaram insuficientes os espaços de solução privilegiada de conflitos, superando-se, para tanto o chamado constitucionalismo provinciano. Nesse sentido, é possível inferir que os problemas que envolvem os direitos humanos e fundamentais, cada vez mais,

${ }^{10}$ NEVES, NEVES, Marcelo. Transconstitucionalismo. São Paulo: Martins Fontes, 2009, p. 265 
caracterizaram-se por sua relevância a níveis globais e exigem a capacidade adaptativa de todos os que visam resguardá-los.

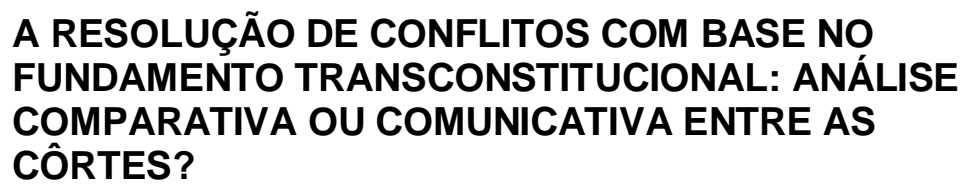

Referem-se os estudos de direito comparado, em realidade, a uma transposição da lei, princípios, conceitos e experiências internacionais que se desenvolveram com o passar do tempo, e possibilitaram uma melhor analise do direito interno. A partir disso, podem ser identificados pontos de convergência e divergência sobre a temática, entre os diversos países do globo.

Essa comparação, nas palavras de Caio Mario Silva Pereira ${ }^{11}$, pode ocorrer no plano horizontal ou vertical. No primeiro, o que se objetiva é a compreensão sobre o comportamento de determinado fenômeno jurídico em diferentes países. Já no segundo, o que se procura é a comparação espacial relativa aos efeitos de cada um desses comportamentos ao longo do tempo, sendo para tanto, de suma relevância, as estatísticas.

Nesse sentido, pode ser que ocorra confusão entre os conceitos de Direito comparado e Transconstitucionalismo. Entretanto, embora haja convergência entre ambos os pensamentos, no sentido de que a observância do estranho permite uma melhor compreensão do sistema local, não podem ser sinônimos, pois se afastam profundamente em seus objetivos finais.

Grande parte da corrente comparatista busca, ainda que de maneira utópica, a uniformização dos institutos jurídicos no plano internacional. Almeja, portanto, segundo LAMBERT ${ }^{12}$, uma aproximação entre os direitos, a partir de um compartilhamento de princípios em comum que viabilizem futura construção e fruição de um sistema único que deverá ser adotado por países que possuam o mesmo grau de civilização.

$\mathrm{O}$ intuito final relaciona-se intimamente com a expectativa de dinamização das relações internacionais, sobretudo para o favorecimento

\footnotetext{
${ }^{11}$ PEREIRA, Caio Mário da Silva. Direito Comparado e o seu Estudo. Revista da Faculdade de Direito Universidade Federal de Minas Gerais, Belo Horizonte, p. 40, v. 7, 1955.

${ }^{12}$ PEREIRA, Caio Mário da Silva. Direito Comparado e o seu Estudo. Revista da Faculdade de Direito Universidade Federal de Minas Gerais, Belo Horizonte, p. 37, v. 7, 1955.
} 
entre as pontes econômicas e políticas, bem como a superação de um direito natural que se faz ultrapassado. Na lição de Inocêncio Mártires Coelho, o direito comparado é um método comparativo que busca necessariamente a compreensão de determinado instituto jurídico.

O direito comparado, essencialmente, é apenas um processo de busca e constatação de pontos comuns ou divergentes, entre distintos sistemas jurídicos a ser utilizado pelo intérprete como um recurso a mais para aprimorar o trabalho hermenêutico ${ }^{13}$.

O transconstitucionalismo, por sua vez, nas palavras de Marcelo Neves, afigura-se como um direito constitucional do futuro, e exige uma grande interdisciplinaridade, tendo em vista que busca constantemente um modelo de articulação entre os sistemas, para que assim ocorra o chamado entrelaçamento transversal, o qual, sobretudo em matéria de direitos humanos ou fundamentais, viabiliza o aprendizado recíproco entre ordens interessadas na resolução de um problema jurídico constitucional que perpassa todas as barreiras físicas e ideológicas, e, consequentemente, proporciona a reconstrução sistêmica de cada um dos envolvidos. Portanto, esse processo não implica em uma simples comparação, mas em um estudo e conversação simultâneos que respeitem as características próprias de cada um dos Estados.

O intercâmbio e o aprendizado com o outro constituem o lado positivo desse entrelaçamento. Mas precisamente porque não há mera convergência, há momentos de colisão que implicam em reafirmação de uma identidade constitucional em detrimento da outra. Essa dialética do transconstitucionalismo implica uma forma de dois lados, sendo o valor positivo a interlocução construtiva entre ordens jurídica ${ }^{14}$.

Contudo, cumpre ressaltar que não se trata o Transconstitucionalismo da submissão de uma ordem jurídica à outra, pois não envolve questões de hierarquia política, mas possui relação com a essência didática do diálogo, a chance de um aprendizado recíproco, a partir da observação das diferentes identidades de cada um desses relacionamentos que podem envolver estados nacionais, supranacionais ou internacionais.

\footnotetext{
${ }^{13}$ COELHO, Inocêncio Mártires, "Métodos e princípios da interpretação constitucional: o que são, para que servem, como se aplicam", Caderno Virtual, Brasília, p. 11, vol. 2. n. 8, 2004.

${ }^{14}$ NEVES, NEVES, Marcelo. Transconstitucionalismo. São Paulo: Martins Fontes, 2009, p. 259.
} 
A Teoria Transconstitucionalista envolve um processo avaliativo da disposição entrecortes de buscar os melhores métodos para aprimorar a interlocução em busca não de um denominador comum para elucidação dos obstáculos constitucionais, mas sim da capacidade de auto-observação, influencia e modificação de soluções aos casos jurídicos concretos, tendo como parâmetros os olhares do outro. O transconstitucionalismo, de forma sucinta, é estabelecido a partir da construção de pontes transversais de conversação e compreensão entre as mais diversas ordens jurídicas, tendo respeitadas as diferenças socioculturais entre elas.

Por conseguinte, esse intercambio congruente deve ser estabelecido por intermédio da troca de conhecimentos conceituais e experiências acessíveis, atribuindo aos participantes a chance de traçar um caminho racional e compatível com a coletividade social. Desse modo, não deve ser deixada de lado a significativa adequação do diálogo transconstitucionalista ao caso concreto, principalmente nas situações em que existam conflitos em relação aos direitos fundamentais. Afinal, não seria possível a utilização da bagagem composta por precedentes jurisdicionais de outras Cortes sem que houvesse um liame correlato à conjuntura da adversidade jurídica a ser superada e a premissa eleita. As trocas são adaptadas de acordo com a realidade que as invoca.

$\mathrm{O}$ intercâmbio e o aprendizado construtivos a que se refere a Teoria, ocorre de diversas maneiras, entretanto, a forma que se destaca para a pesquisa em questão é a instauração das pontes de conversação transversais por meio de Juízes e Tribunais, os quais são, segundo o autor daquela, o centro de um sistema jurídico multicêntrico.

Sendo assim, imprescindível se torna o desígnio desses agentes para compreender outros centros, sem que, para tanto, ocorra a desconsideração das particularidades de cada ordem jurídica. O respeito à identidade se faz imprescindível para viabilizar a transformação por alteridade inerente à pluralidade de ordens jurídicas.

No Brasil, tem sido muito utilizado o posicionamento de outro país para que, a partir de uma complementaridade de matérias, seja obtida um posicionamento jurisdicional apropriado. A constante menção aos Estados estrangeiros, tem sido operada com o objetivo de encontrar respaldos que levem à melhor resposta jurídica, política e social para o que está a ser demandado. Portanto, nesses casos, a referência à outras ordens jurídicas, procede como importante ferramenta para formação da ratio decidendi.

Desse modo, preleciona Marcelo Neves: 
O transconstitucionalismo faz emergir, por um lado, uma fertilização constitucional cruzada". as cortes constitucionais citam-se reciprocamente não como precedentes, mas como autoridade persuasiva ${ }^{15}$.

Não obstante, esse dissenso deve ocorrer de maneira pontual porque não requer um diálogo permanente, a fim de evitar choques irreversíveis de perspectivas jurídicas. SOBRE A DESCRIMINALIZAÇÃO DO ABORTO NO BRASIL

Uma das questões que atordoam as réplicas jurisdicionais ao caso concreto diz respeito à ponderação de princípios no ordenamento jurídico brasileiro. Enquanto ferramenta para aplicação do direito há uma tendência doutrinária em enfatizar excessivamente a aplicação desses, e, inclusive, questionar a possibilidade de categorizá-los por grau de importância, por isso se tornam preocupantes as dúvidas em torno da perfeição dos princípios.

Destarte toda faculdade do legislador de utilizar-se desses em busca de pronunciamentos justos, não existem princípios absolutos, logo não há razão para qualifica-los como mais ou menos fundamentais, mas sim a possibilidade de pondera-los em face das súbitas demandas da sociedade hodierna.

Para Neves, a teoria transconstitucionalista emerge da necessidade de ampliação do alcance da norma jurídica, bem como da possibilidade de aprendizado entre cortês sobre assuntos que tratem não apenas da limitação do poder, mas, principalmente, dos direitos humanos, referências para essa pesquisa em questão.

[...] A questão dos direitos humanos, que surgiu como um problema jurídico-constitucional no âmbito dos Estados, perpassa hoje todos os tipos de ordens jurídicas no sistema mundial de níveis múltiplos: ordens estatais, internacionais, supranacionais, transnacionais e locais ${ }^{16}$.

\footnotetext{
${ }^{15}$ NEVES, Marcelo. Transconstitucionalismo. São Paulo: Martins Fontes, 2009, p. 119.

${ }^{16}$ NEVES, Marcelo. Transconstitucionalismo. São Paulo: Martins Fontes, 2009, p. 256.
} 
Nesse diapasão, o conflito de interesses entre a demanda social por avanços técnico-científicos e políticos-jurídicos em face da dificuldade de adaptação das normas aos casos concretos, ultrapassaram as barreiras dos conflitos domésticos, reservados aos territórios estatais para entender os mesmos problemas sob os pontos de vistas de ordenamentos jurídicos diversos.

A partir disso, se inicia um debate acerca da eficiência da pratica constitucional ao instaurarem-se pontes transnacionais de conversação entre as ordens jurídicas (estatais, internacionais, supranacionais), a fim de não apenas aferir novos precedentes estrangeiros para o debate acerca da descriminalização do aborto no Brasil, como se faz pelo uso do direito comparado - ratio decidendi - mas alcançar, de fato, um novo olhar sobre problemas de natureza constitucionais congêneres à função judiciária em âmbito global.

A fim de esclarecer a questão é importante a análise dos julgados recentes sobre o tema, a partir do estudo da influência dessa margem teórica sobre os julgados do STF no Brasil, atentando-se à importância jurisprudencial da ADPF 54 e do recente $\mathrm{HC} \mathrm{n}^{\circ} 124.306$, como ferramenta para formação de uma nova perspectiva jurídica sobre o assunto.

Destaca-se também a relevância das conversações, entre as diferentes ordens jurídicas que compõem o globo, para alcançar uma resposta madura sobre o ponto de vista desamarrado de crenças pessoais e tabus limitantes, ao trazer os conceitos de alteridade para melhor compreensão de sua identidade estatal.

\section{A JURISPRUDÊNCIA CRIADA PELO STF - ANÁLISE DA ADPF 54}

O julgamento da $\mathrm{ADPF}^{17}$ foi proposto pela Confederação Nacional dos Trabalhadores na saúde, e, em razão de sua relevância, elevou a compreensão sobre diferentes reflexões em relação aos conceitos multifacetados de vida e morte, sob o viés jurídico, político, social, científico, filosófico e religioso. O STF, visando o resguardo e proteção da

\footnotetext{
${ }^{17}$ BRASIL. Supremo Tribunal Federal. Arguição de Descumprimento de Preceito Fundamental n. 54 - DF. Relator: Ministro Marco Aurélio, julgado em 12/4/2012, publicado em 30/4/2013. Disponível em:

$<$ http://www.stf.jus.br/portal/peticaoInicial/verPeticaoInicial.asp?base=ADPF\&s 1=54\&processo=54> . Acesso em 9 set. 2018.
} 
Constituição Federal, decidiu a questão relativa ao abortamento nos casos de anencefalia, sob o prisma essencialmente jurídico, mas, para tanto, se utilizou de informações de cunho científico e cultural, mediante a terceira audiência pública no Brasil, para que se iluminasse o debate.

Foi importantíssima, nesse sentido, a participação de quatorze pessoas, na figura de amicus curiae, dentre essas, religiosos e cientistas para a discussão do caso, com quinze minutos cada para defesa de uma tese favorável ou contrária, desde que fundamentada, à legalização dos abortos realizados em decorrência de anomalia gravíssima que inviabilize totalmente a vida extrauterina.

Tendo em vista que a vida humana, uma vez reconhecida, é intangível e, portanto, inviolável, a decisão foi socialmente revolucionária ao considerar a possibilidade de assegurar os direitos da mulher, em face do produto da concepção que a partir dela se desenvolve. A linha de raciocínio traçada identificou a não adequação da conduta ao tipo penal, por não considerar o feto anencefálico um ser humano com vida, tendo como respaldo os critérios médicos que apontam para a absoluta impossibilidade de autonomia, quando da incidência dessa doença sobre o feto.

A decisão se fundamentou em duas outras questões legalmente previstas por nosso ordenamento jurídico pátrio: a Lei de Transplante de $\mathrm{n}^{\circ}$ 9.434/97, em que há a garantia normativa de que possam ser realizados os procedimentos de transposição de órgãos, nos casos em que for documentalmente comprovada a cessação da atividade cerebral de um indivíduo, sendo imprescindível o atestado conferido por médico capacitado.

Cumpre ressaltar ainda que, os profissionais se diferenciam em suas funções, a fim de evitar conflitos de interesses de qualquer natureza. Portanto, aquele que atesta o fim da atividade cerebral, não fica incumbido da responsabilidade de transplantar. Logo, a lei de Transplante de órgãos está alicerçada na percepção de que, em razão de juridicamente a morte ser compreendida como a cessação da atividade cerebral, é possível que aqueles sejam manipulados para salvar outras tantas vidas.

No caso da Anencefalia, o entendimento foi o mesmo, de que, a partir do atestado médico de que não haverá a formação do córtex cerebral, e, consequentemente, o desenvolvimento vital do sistema nervoso central, o qual nos singulariza enquanto seres racionais autônomos, não há o que se falar em afetação da dignidade, pois esta situação pressupõe o fim do produto da concepção que nunca veio a possuir status humano. 
Sendo assim, o Supremo Tribunal Federal considerou ser, sob essas circunstâncias, a prática de aborto uma conduta atípica, sem a necessidade de autorização judicial a cada caso. O médico possui a faculdade de, com o consentimento da gestante, realizar o abortamento, quando identificar a anencefalia fetal. Sendo assim, a mulher deixa de suportar o ônus físico e psíquico de prosseguir forçosamente com uma gestação absolutamente inviável, onde restariam todas as expectativas, inerentes à maternidade, frustradas.

A segunda base argumentativa foi a hipótese legal acerca do aborto sentimental nos casos em que a mulher tenha sofrido violência sexual que resulta em uma gestação, não apenas indesejada, mas temida, elevando o dissabor do trauma pelo qual tenha passado. No sentido humanitário da análise de cada um desses casos concretos, identifica-se como moralmente impossível que a mulher, após um crime tão bárbaro seja obrigada a dar luz a uma criança que carrega em si o código genético de seu agressor e a imagem de toda a dor a qual foi sujeita a vítima. Não sendo consideradas aqui teses sobre a saúde do feto, pois seria essa desimportante em face da urgência de zelar pela mulher, em observância ao princípio da dignidade da pessoa humana.

Em análise aos aspectos principais dos votos de cada ministro, cumpre ressaltar a respeitável posição favorável à possibilidade de praticar o aborto nos casos de anencefalia, proferida pelo Relator Ministro Marco Aurélio, a seguir demonstrada.

Em um primeiro momento, destaca-se que o objeto de discussão pelo Tribunal, foi justamente a declaração de inconstitucionalidade da interpretação dos artigos 124, 126 e 128, incisos I e II, do Código Penal, os quais disciplinam sobre o abortamento no Brasil e cuja interpretação criminalizava a prática à época, salvo nos casos de a manutenção da gravidez resultar em grave risco de vida à gestante ou decorrer da prática do crime de estupro. Sendo essencial que o STF fizesse o controle de constitucionalidade e atribuísse a interpretação sob o seio da Constituição Federal de 88.

Por conseguinte, o relator demonstrou enfaticamente seu repúdio aos termos utilizados por grande parte da doutrina que atribuía a esse caso de antecipação da gravidez dos fetos anencefálicos uma forma de aborto eugênico, pois não se trata da escolha de um padrão imoral a ser feito para formação de um tipo de sociedade perfeita e livre de deficiências. Afinal, o feto anencéfalo não possui deficiência, pois esta pressupõe a capacidade 
de viver, ainda que com limitações, fora do útero materno, ao passo que aquela não prevê essa possibilidade.

Ademais, constantemente discorreu sobre a importância da laicidade do Estado brasileiro, consagrada na Constituição Federal de 88, em seu artigo 19, inciso I, que assegura a não intervenção do Estado na esfera religiosa, além de impossibilitar que esse seja influenciado de maneira indevida por qualquer que seja o credo. Nesse diapasão, o Estado não dispõe de capacidade renunciadora dos direitos fundamentais, em face de uma moral religiosa.

Isto posto, a Arguição de Preceito Fundamental destacou a sobreposição total da atenção aos direitos fundamentais que deveriam ser sempre resguardados às mulheres, a exemplo do direito à autodeterminação, saúde física e mental, privacidade e direito à liberdade no campo da reprodução.

Deste jeito, o anencefálico foi considerado pelo Relator como sendo um natimorto neurológico, em razão de sua doença congênita letal, e, portanto, não haveria o que se falar em presunção de vida extrauterina, tendo em vista a incompatibilidade entre os conceitos de anencefalia e vida, o que corrobora para o entendimento de que a mulher deve ter o direito de se preservar em face da dor que inevitavelmente sofreria pela perda de uma vida, desde o princípio, impossível.

\footnotetext{
Enquanto, numa gestação normal, são nove meses de acompanhamento, minuto a minuto, de avanços, com a predominância do amor, em que a alteração estética é suplantada pela alegre expectativa do nascimento da criança; na gestação do feto anencéfalo, no mais das vezes, reinam sentimentos mórbidos, de dor, de angústia, de impotência, de tristeza, de luto, de desespero, dada a certeza do óbito.
}

A ideia de que um feto inviável deve ser resguardado em detrimento das previsões constitucionalmente tidas como essenciais para a qualidade de vida de todos os indivíduos, e, nesse caso, em face das garantias sobre o princípio da dignidade da pessoa humana e os direitos fundamentais à autonomia, privacidade, saúde e integridade da mulher, se refuta absurdamente injusta, não devendo, dessa forma, ser acolhida. 
O Estado deve assegurar a manifestação da autonomia da vontade mulher, pois esta é um ser uno e capaz de elencar os valores morais que conduzirão suas manifestações no mundo social. Portanto, não é possível que a sociedade a obrigue à manutenção de uma gestação que resultará em nada além de dor, por desejo desumano de se instrumentalizar um corpo sobre o qual ninguém se responsabilizaria em amenizar o sofrimento da perda.

A incolumidade física do feto anencéfalo, que, se sobreviver ao parto, o será por poucas horas ou dias, não pode ser preservada a qualquer custo, em detrimento dos direitos básicos da mulher ${ }^{18}$.

Ainda que não com o intuito de promover um debate transconstitucional, é importante destacar dois outros trechos do voto acima citado. A princípio, no sentido de promover a linha de pensamento para a antijuridicidade da conduta de abortamento nos casos de feto anencefálico, o Relator citou que a vida não deve ser tida como valor constitucional absoluto, mencionando para tanto um trecho da decisão da Corte Italiana que declarou a inconstitucionalidade parcial de normas que tipificavam a conduta do abortamento.

[...] o interesse constitucionalmente protegido relativo ao nascituro pode entrar em colisão com outros bens que gozam de tutela constitucional e que, por consequência, a lei não pode dar ao primeiro uma prevalência absoluta, negando aos segundos adequada proteção. E é exatamente este vício de ilegitimidade constitucional que, no entendimento da Corte, invalida a atual disciplina penal do aborto [...] Ora, não existe equivalência entre o direito não apenas à vida, mas também à saúde de quem já é pessoa, como a mãe ${ }^{19}$, e a salvaguarda do embrião, que pessoa ainda deve tornar-se.

Essa citação sobre a decisão de Tribunal Constitucional Estrangeiro serviu para a formação da ratio decidendi do Relator no sentido de que não deveria ser atribuída à mulher uma pena por preservar sua saúde em detrimento de um feto sem vida, no sentido técnico demonstrado anteriormente. Dessa forma, restou consolidada a compreensão de que a mulher precisa da segurança acerca de seus direitos fundamentais e do conteúdo de dignidade que cada um deles carrega em si, pois não deve ser

\footnotetext{
${ }^{18}$ BRASIL. Supremo Tribunal Federal. Arguição de Descumprimento de Preceito Fundamental n. 54 - DF, voto Ministro Marco Aurélio, p. 71.

${ }^{19}$ SARMENTO, Daniel. Livres e Iguais: estudos de direito constitucional. Rio de Janeiro: Ed. Lumem Iuris, 2006.
} 
compelida a manter uma gestação tortuosa, sob pena de o Estado ao criminalizar a conduta, não resolver o problema, mas tão somente agraválo.

Num segundo momento, o Ministro traz à sua fundamentação outra decisão, dessa vez elaborada pelo comitê de Direitos Humanos da Organização das Nações Unidas, a qual disciplinou sobre o "Caso K.L. contra Peru", em que foi sentenciado como sendo o ato de criminalizar a conduta do abortamento de fetos anencéfalos, equiparável à tortura. No cenário em questão, uma jovem de 17 anos havia sido obrigada a parir um feto acometido por anencefalia, pois ainda que a ordem jurídica peruana ${ }^{20}$ não se opusesse ao aborto necessário e conferisse pena irrisória aos casos de aborto sentimental ou eugênico e a jovem tivesse optado por não continuar com a gravidez, não foi possível a obtenção de autorização necessária para a realização do ato cirúrgico.

Destarte, o feto não sobreviveu por mais de quatro dias, mas os impactos de uma gestação indesejada e inviável perduraram por muito tempo, tendo sido desenvolvido na adolescente um grave quadro de depressão. Para o comitê, a não concessão de permissão para o procedimento foi postura desumana, o que para o Relator da ADPF 54 poderia ter sido totalmente evitado, não devendo o Estado brasileiro continuar a se omitir em face da demanda social e da questão de saúde pública aqui discutidas.

Por fim, em observância à necessidade de uma resposta jurisdicional eficiente para o assunto controverso, bem como do amálgama de argumentos já apresentados, o Ministro julgou procedente o pedido formulado na Inicial para o reconhecimento de inconstitucionalidade da interpretação que apontava o abortamento de fetos anencefálicos conduta tipificada pelo Código Penal brasileiro.

\footnotetext{
${ }^{20}$ Os artigos do Código Penal Peruano dispõem sobre o aborto no sentido de que:

Art. 119 - Aborto Terapêutico

Não é punível o aborto praticado por um médico com o consentimento da mulher grávida ou de seu representante legal, se o tiver, quando é o único meio para salvar a vida da gestante ou para evitar um mal grave e permanente em sua saúde.

Art. 120 - Aborto Sentimental

O aborto será reprimido com pena privativa de liberdade não maior que três meses: I - Quando a gravidez seja consequência de violação sexual fora do matrimônio ou inseminação artificial não consentida e ocorrida fora do matrimônio, sempre que os fatos tiverem sido denunciados ou investigados, ao menos policialmente; ou II - Quando é provável que o ser em formação leve a um nascimento com graves defeitos físicos ou psíquicos, sempre que exista diagnóstico médico.(Cópia eletrônica disponível em https://apps.contraloria.gob.pe/unetealcontrol/pdf/07_635.pdf. Acesso em 10 de setembro de 2018).
} 
Os votos favoráveis ao entendimento do Relator Marco Aurélio foram Rosa Weber, a qual considerou ser necessário que o Estado não demonstre interesse jurídico na manutenção de um feto inviável, sendo imprescindível que assegure a liberdade individual às mulheres, para que essas possam optar por interromper a gestação de forma segura. Já para o Ministro Luiz Fux, as ciências médicas avançaram num sentido tecnológico capaz de auferir a eficiente e rápida constatação de anencefalia fetal, fato que ainda não era possível quando da elaboração do Código Penal. Sendo assim, a criminalização, por não influir de forma significativa sobre os números da prática do abortamento, não deveria ser compreendida como eficaz, devendo, portanto, a temática ser atribuída à urgência de saúde pública, e a mulher atribuído o direito de ser orientada e optar pela interrupção ou não da gravidez.

Ao ponto de vista da Ministra Carmem Lucia, a mulher deve ser amparada pelo Estado, não devendo, de forma alguma, sua opção por antecipar a gestação criminalizada, pois ela já sofre com a notícia de inviabilidade da gravidez. Por outro lado, o ministro Ayres Britto, à época, afirmou que a interrupção da gestação não deveria ser tratada como um aborto, mas que a mulher deveria ter sua decisão respeitada, não sendo obrigada a levar adiante uma gestação que se resultará frustrada. No mesmo raciocínio, Celso de Mello afirmou não se tratar a hipótese dos casos tipificados pelo Código Penal brasileiro, pois ao feto nunca foi atribuída vida, não devendo a prática abortiva significar sua morte.

Gilmar Mendes compreendeu ser a tipificação do código penal ultrapassada nesse sentido, pois as ciências médicas avançaram para um diagnóstico eficaz para uma rápida identificação da anomalia que impossibilite a vida extrauterina do feto. Assim, a interrupção da gestação de fetos anencefálicos constitui uma forma de se proteger a saúde da mulher e assegurar sua dignidade.

Os votos contrários foram elaborados pelos Ministros Lewandowski e Cezar Peluso, pois para este o aborto não deveria ser descriminalizado, tampouco ponderado em face da situação fática descrita, uma vez que o feto anencefálico seria sim dotado de vida e, portanto, certo seu direito à vida. Entretanto para Lewandowski, a situação não deveria ser discutida no âmbito jurídico, mas sim sob a esfera do legislativo, atestando a ilegitimidade do Supremo Tribunal Federal julgar o mérito da questão.

A apreciação positiva por parte do Supremo Tribunal Federal gerou efeito vinculante ao constatar que, em nome dos direitos fundamentais e reprodutivos das mulheres, foi necessária a reinterpretação, 
em conformidade com a Constituição Federal, dos dispositivos que disciplinavam acerca do tema no Código Penal, pois a criminalização do aborto viola a autonomia da mulher de ser, pensar e escolher o projeto de vida que pretenda seguir, instrumentalizando-a enquanto uma simples parideira a serviço da sociedade.

Os elementos que serviram para formar a convicção dos magistrados foram não apenas os dados científicos trazidos por parte dos oradores, tendo sido extremamente interessante a observação do entendimento de outros tribunais constitucionais acerca do mesmo assunto. Afinal, as decisões estrangeiras foram essenciais para a formação dos argumentos que viriam a constituir a decisão final.

A menção aos casos estrangeiros iniciou a reinterpretação sobre os elementos fáticos do caso concreto brasileiro, tendo em vista a disposição por parte dos ministros em não apenas cita-los, mas também utilizá-los como um ponto de vista necessário para um debate justo sobre o tema. Além disso, a experiência internacional demonstrou o atra so da lei nacional em discutir tardiamente um fato recorrente no quadro de saúde brasileira.

Os argumentos ora apresentados solidificam o hoje o entendimento acerca da ampliação da possibilidade de abortamento sem responsabilização penal, como será demonstrado a seguir.

\subsection{HC 124.306}

Em novembro de 2016, o Supremo Tribunal Federal decidiu, por intermédio de um acórdão, que seria realizada a soltura de médicos e funcionários de uma clínica de aborto clandestina, seguindo um raciocínio jurídico que não entendia ser o aborto no primeiro trimestre gestacional passível de tipificação penal, a responsável por violar os direitos fundamentais das mulheres ${ }^{21}$.

Ainda que não se trate de uma decisão vinculativa, tornou-se jurisprudencial e abriu espaço para um debate de importância científica, jurídica e social de caráter transconstitucionalista, renascendo no país a incessante busca por respostas às seguintes perguntas: seria a

\footnotetext{
${ }^{21}$ BRASIL. Supremo Tribunal Federal. Habeas Corpus n. 124.306-RJ. Relator: Ministro Marco Aurélio, julgado em 29/11/2016. Disponível em: $<$ http://redir.stf.jus.br/paginadorpub/paginador.jsp?docTP=TP\&docID=12580345>. Acesso em 9 set. 2018.
} 
descriminalização do aborto no Brasil uma forma de se melhorar a saúde pública, evitando a morte de milhares de mulheres anualmente vítimas do procedimento inseguro? Qual a eficácia da legalização do aborto no direito comparado? E, por fim, até que ponto são respeitados os direitos da mulher no plano nacional?

O Código Penal foi inaugurado com o pensamento legislativo correspondente à década de 1940. Sendo assim, necessita ser readequado à hodierna conjuntura jurídica e política do Brasil, pois como demonstrado nos capítulos anteriores, é inegável a sistematização e complexidade da sociedade plural que emerge na Era pós-positivista.

As relações interpessoais se intensificaram em um lapso temporal relativamente curto, o que transformou a dinâmica organizacional e de conduta do corpo social como um todo. Entretanto, a legislação não foi capaz de acompanhar de forma eficiente as novas demandas sociais, produzindo respostas jurisdicionais, muitas vezes, desconexas da nova realidade fática a ser compreendida em cada caso concreto.

É nítido que a elaboração de um dispositivo legal depende diretamente do poder legislativo, não cabendo a interferência do judiciário na criação de novas leis. Por outro lado, também é indiscutível que a formalização das normas passa por processo essencialmente político, e, portanto, submetem-se aos jogos de interesses, os quais não objetivam a resolução dos problemas sociais, mas a manutenção de um comodismo autoritário.

É papel do Judiciário, no âmbito de atuação do Supremo Tribunal Federal, conferir a interpretação das leis infraconstitucionais em conformidade com os propósitos ideias da Carta Maior de 1988. Sendo assim, os artigos $124^{22}$ e $126^{23}$ do Código Penal brasileiro foram reinterpretados para integração dos conteúdos disciplinados, aos casos de interrupção da gestação até a décima segunda semana de gravidez. Nesse sentido, é importante que sejam destacados alguns pontos relevantes sobre a decisão do Ministro Luís Roberto Barroso sobre o caso, como será demonstrado abaixo.

Entende-se que o conceito de aborto é a interrupção da vida intrauterina com total extinção do produ to resultante da concepção e que para qualificar um tipo penal de pleno acordo com a Constituição Federal deve preencher três requisitos: atender a um bem jurídico relevante; o

\footnotetext{
${ }^{22}$ Art. 124. Provocar aborto em si mesma ou consentir que outrem lhe provoque: Pena - detenção, de um a três anos.

${ }^{23}$ Art. 126. Provocar aborto com o consentimento da gestante: Pena- reclusão de um a quatro anos.
} 
comportamento incriminado não pode constituir exercício legítimo de um direito fundamental e deve haver proporcionalidade entre a ação praticada e a reação estatal.

Para Barroso, a criminalização do aborto não é eficaz, pois não evita que a prática ocorra, mas força a clandestinidade, em especial das mulheres pobres, a qual transforma o tema em questão de saúde pública. Afinal, em consideração aos dados expressos por órgãos de saúde atuantes no país, hoje é uma das maiores causas de morte materna.

Segundo a fala do Ministro, trata-se da discussão a respeito de um direito fundamental, portanto não pode a questão ser subordinada ao poder do legislador. Refere-se a um conjunto de liberdades que constituem uma reserva mínima de justiça que decorre diretamente de um direito natural. Sendo assim, se o legislador atuar de forma contrária ao direito fundamental estará atuando de forma ilegítima e inválida.

A criminalização do aborto é um marco infeliz nas estatísticas dos países subdesenvolvidos e emergentes, pois quando comparadas as legislações do globo, o Brasil em muito está atrasado ao debate. Ainda, o Ministro citou como exemplo dos países desenvolvidos que não tipificam a conduta de interromper a gestação no primeiro trimestre gestacional os Estados Unidos, Alemanha, Reino Unido, Canadá, França, Itália, Espanha, Portugal, Holanda e Austrália. Esses programaram política alternativa a fim de que, se preenchidos os requisitos procedimentais, as mulheres sejam previamente aconselhadas clinicamente, e não penalizadas em momento de tamanha fragilidade pessoal.

Alguns dos países supracitados são reconhecidamente religiosos, mas não impediram o debate e a devida resposta Estatal aos problemas acarretados pela necessidade de se garantir a segura interrupção da gravidez indesejada, não como meio de inibir a autonomia ou crença de cada indivíduo, mas para assegurar o respeito à liberdade de autodeterminação.

Sob os aspectos do transconstitucionalismo, é importante ressaltar ainda que o Ministro citou decisão do Tribunal Federal Alemão para demonstrar a ineficácia da legislação que pune as mulheres ao invés de preservá-las, o que provoca o efeito estatístico inverso do pretendido pelo legislador. 
O sigilo relativo ao nascituro, sua impotência e sua dependência e ligação única com a mãe, as chances do Estado de protegê-lo serão maiores se trabalhar em conjunto com a mãe. ${ }^{24}$

Além disso, demonstrou que o Estado possui alternativas mais eficientes para evitar a interrupção das gestações, ainda com base no exemplo Alemão de disponibilizar toda estrutura médica à mulher que deseje abortar no estágio inicial da gravidez. Dessa forma, o acompanhamento do caso pode levar a uma reflexão de suas consequências, o que leva a uma decisão bem ponderada por parte da gestante.

Outrossim, outros julgados estrangeiros foram referenciados ao tema, a exemplo do caso de "Roe v. Wade, julgado pela Suprema Corte dos Estados Unidos, em que foi decretado a submissão do interesse estatal sobre a proteção da vida fetal ao direito de a mulher optar pela realização de um aborto. Ademais, a declaração de inconstitucionalidade da criminalização do aborto proferida pela Corte Suprema de Justiça do Canadá também seria a demonstração clara da ineficiência da norma penal brasileira em disciplinar sobre conteúdo de relevância internacional.

\footnotetext{
De acordo com o regime de adotado em diversos países (como Alemanha, Bélgica, França, Uruguai e Cidade do México), a interrupção da gestação não deve ser criminalizada, pelo menos, durante o primeiro trimestre da gestação. Durante esse período, o córtex cerebral - que permite que o feto desenvolva sentimentos e racionalidade - ainda não foi formado, nem há qualquer potencialidade de vida fora do útero materno ${ }^{25}$.
}

Infere-se, portanto, que a influência do voto do Ministro Barroso pode ser intimamente relacionada com o debate transconstitucionalista, pois por meio de decisão do Supremo Tribunal Federal, casos emblemáticos acerca do tema, disciplinados por tribunais estrangeiros serviram de instrumento para a formação da convicção do aplicador do direito.

Nessa decisão não há simples menção às normas escritas de outros países, mas a preocupação em realizar um debate de relevância para além do lócus do estado nacional, sobre a perspectiva de outras culturas e formação social. O olhar do outro para a formação de uma visão interna

\footnotetext{
${ }^{24}$ BRASIL, Supremo Tribunal Federal. Habeas Corpus n. 124.306 - RJ. Relator: Ministro Marco Aurélio, julgado em 29/11/2016.

${ }^{25}$ SARMENTO, Daniel. Livres e Iguais: estudos de direito constitucional. Rio de Janeiro: Ed. Lumem Iuris, 2006.
} 
mais consciente e que proporcione uma resolução mais compatível com o caso concreto.

Ainda que não seja possível dizer que os Ministros do Supremo Tribunal Federal têm se empenhado no desenvolvimento de raciocínio transconstitucionalista por completo, é indiscutível a presença de elementos que demonstrem que, de fato, os problemas constitucionais, sobretudo os de direitos humanos e fundamentais, ultrapassaram as barreiras dos Estados e se tornaram concomitantemente relevantes para tantas outras ordens jurídicas.

\section{$7 \quad$ CONCLUSÃO}

Foi possível auferir o entendimento de que o intercâmbio didático entre os diferentes Tribunais Constitucionais é capaz de transformar os impasses nacionais de forma justa, pois evidencia a necessidade de um constante reexame acerca dos dispositivos legais e suas interpretações, seguindo o entendimento de que a sociedade evolui e o sistema normativo, como um todo, responsável por tutelar os direitos, deve acompanhar o seu progresso. É o Estado o responsável por promover a Dignidade da Pessoa Humana a todos os indivíduos brasileiros, bem como assegurar os demais direitos fundamentais previstos na Constituição de 1988.

O fenômeno do transconstitucionalismo promovido pelos Tribunais nacionais elevam a conscientização do ordenamento jurídico pátrio ao compará-lo com os julgados estrangeiros, os quais servem, cada vez mais, como ferramenta de fundamentação das decisões por parte dos magistrados.

Em análise aos casos da ADPF 54 e o julgamento do HC 124.306, foram identificados não só aspectos do direito comparado, mas também da Teoria Transconstitucionalista. Os julgados buscaram a inserção do direito nacional em um contexto de conhecimento pluridimensional, provando a necessidade dos estudos de matérias interdisciplinares para uma resposta jurisdicional justa. Além disso, os precedentes trazidos à baila das decisões solidificam o entendimento de que já passou da hora de o sistema jurídico e político brasileiro se adequar à sociedade diversificada e progressivamente consciente de seus direitos e deveres para o convívio harmônico entre todos.

A disposição em estabelecer pontes de conversação, ainda que de forma pontua e em observância às características exclusivas do contexto 
sociocultural de cada Estado, evidencia que o Transconstitucionalismo, de fato, é um direito constitucional do futuro, pois exige o desenvolvimento da tolerância e capacidade de autocrítica construtiva.

\section{REFERÊNCIAS BIBLIOGRÁFICAS}

BARROSO, Luís Roberto. Palestra A Liberdade de ser: Morte, vida e escolhas existenciais, ABL, 2016.

BRASIL. Constituição (1988). Constituição da República Federativa do Brasil. Brasília, DF. Disponível em: < http://www.planalto.gov.br/ccivil_03/constituicao/constituicaocompilado.htm>. Acesso em 9 set. 2018

Supremo Tribunal Federal. Arguição de Descumprimento de Preceito Fundamental n. 54 DF. Relator: Ministro Marco Aurélio, julgado em 12/4/2012, publicado em 30/4/2013. Disponível em:

$<\mathrm{http} / /$ www.stf.jus.br/portal/peticaoInicial/verPeticaoInicial.asp?base=ADPF\&s 1=54\&processo=54> . Acesso em 9 set. 2018

Supremo Tribunal Federal. Habeas Corpus n. 124.306-RJ. Relator: Ministro Marco Aurélio, julgado em 29/11/2016. Disponível em:

$<$ http://redir.stf.jus.br/paginadorpub/paginador.jsp?docTP=TP\&docID=12580345>. Acesso em 9 set. 2018.

Lei n. 9.434, de 4 de fevereiro de 1997. Dispõe sobre a remoção de órgãos, tecidos e partes do corpo humano para fins de transplante e tratamento e dá outras providências. Brasília, DF. Disponível em:< http://www.planalto.gov.br/CCIVIL_03/Leis/L9434.htm>. Acesso em 9 set. 2018.

Código Penal. Decreto-lei n. 2.848, de 7 de dezembro de 1940. Rio de Janeiro, RJ.

Disponível em: < http://www.planalto.gov.br/ccivil_03/decreto-lei/Del2848compilado.htm>. Acesso em 29 jul. 2018.

CANOTILHO, José Joaquim Gomes. Direito constitucional e teoria da constituição. Coimbra: Almedina, 1997.

COELHO, Inocêncio Mártires, "Métodos e princípios da interpretação constitucional: o que são, para que servem, como se aplicam", Caderno Virtual, Brasília, vol. 2. n. 8, 2004.

NEVES, Marcelo. Transconstitucionalismo. São Paulo: Martins Fontes, 2009.

PEREIRA, Caio Mário da Silva. Direito Comparado e o seu Estudo. Revista da Faculdade de Direito Universidade Federal de Minas Gerais, Belo Horizonte, p. 35-51, v. 7, 1955.

SARMENTO, Daniel. Livres e Iguais: estudos de direito constitucional. Rio de Janeiro: Ed. Lumem Iuris, 2006. 
SILVA, José Afonso da. Aplicabilidade das Normas Constitucionais. Ed. Malheiros: São Paulo, 2007.

SCHIER, Paulo Ricardo. Novos Desafios da Filtragem Constitucional no Momento do Neoconstitucionalismo. A\&C de Dir. Administrativo e Constitucional, Belo Horizonte, ano 5, n. 20, p. 1-255, abr./jun.2005. 